\title{
ADULTS READING ALOUD: A SURVEY OF CONTEMPORARY \\ PRACTICES IN BRITAIN
}

by SAM DUNCAN and MARK FREEMAN, UCL Institute of Education, London

\begin{abstract}
While much is written about reading aloud to children, and as a teaching tool, far less is known about the oral reading that adults do at home, at work or in the community. This article presents the results of a national survey into whether, what, how and why adults across Britain may read aloud rather than in silence. Analysing data from 529 questionnaire responses, the article examines the frequency with which different text types are read aloud, the formations in which this is done - alone, with one other person or in a group - and the purposes of reading aloud and being read to, with attention to differences according to gender and age. Findings suggest that reading aloud happens in a number of different ways and for different purposes, across contexts and life domains, and that it has a significant relationship with aspects of the lifecourse and with identity formation and performance.
\end{abstract}

Keywords: reading aloud, literacy as social practice, adult reading, everyday reading, adult literacy 


\section{INTRODUCTION}

In C. P. Snow's 1960 novel, The Affair, a retired couple, Alice and Paul Jago, are visited by the narrator, Lewis Eliot, who notices a rack of books:

'Ah, those are the books we're reading to each other just now. That was a good custom your generation didn't keep up, wasn't it?'

[Paul Jago] was saying that one of them read to the other for an hour each evening, taking it in turns. That winter they had been 'going through' Mrs Gaskell. It all seemed serene ... they truly were at peace together, more than most couples in retirement, provided they were left alone. (Snow, 1960, p. 184)

This brief comment from the mid-twentieth century suggests that reading aloud could play an important part in sustaining personal relationships; it also raises a sense of regret about an apparently lost literacy practice. The implication, perhaps, was that the new media of the twentieth century, most notably the radio and television, had undermined shared reading experiences. Almost sixty years later, there is a longestablished ethnography of literacy (see for example Brice-Heath, 1983, 2012; Boyarin, 1993; Besnier, 1995), which emphasises the social dimensions of reading and its role in developing and sustaining relationships within communities and families. This is aligned with the New Literacy Studies conceptualisation of literacy as social practice, with literacy as 'ideological' rather than 'autonomous' (Street, 1984; Street, 2003; Barton and Hamilton, 1998; Gebre et al., 2009). Both of these intertwining traditions suggest, in Radway's (1994, p. 278) words, that reading can be 'a thoroughly transformative and deeply social process'. Group practices have always been important: as Radway (1994, p. 275) notes, '[w]hile reading is indeed sometimes 
very private and can function as an occasion for personal reflection, it can also be an activity that is engaged in collectively within the communal embrace of a familiar group.'

Our particular focus here is on an activity which can in fact be - to borrow Radway's terms -'private' or 'communal': the practice of reading aloud. Although, as noted below, some ethnographies of reading have included examples of reading aloud, this element of literacy - whether it occurs with others, as with partners reading to each other, a poet performing live or in an Internet recording, for example, or entirely alone, as when a solitary reader speaks out the words on a page in order to aid comprehension - has been largely downplayed or ignored in the existing scholarship. Much is written (see for example Westbrook et al., 2018; Pergams, 2018; Duncan and Paran, 2018) about reading aloud as a means to an end - as a teaching and learning tool, for example - but little about it as an end in itself: a real-life adult literacy practice. The extent and range of contemporary adult reading aloud has not been adequately documented, and we make a start on this endeavour here. We use a newly collected dataset to address the following questions:

- Do adults read aloud? If so, where, when, why and how?

- When, where, why and how do adults listen to others reading aloud?

- What roles do reading-aloud practices play in adult lives, and does this vary among different groups, for example between men and women or across the lifecourse?

We will show that almost all adults in this study read aloud. Reading aloud occurs in different ways and with different forms of importance in the domains of work, family, 
leisure and religious observance. For some of these adults, reading aloud plays a key role in identity construction. Yet also, and importantly, reading aloud is an often unremarked and even unnoticed activity - indeed, our research has itself raised awareness of reading aloud among some of those who participated in it. This has implications, we will argue, not only for how we understand the role of reading in adult life, and for future research in this area, but also for how reading is conceptualised within education.

\section{CONTEXT}

The historiography of literacy has featured considerable debate about the nature and extent of silent reading practices in the past. Vincent (2000) shows that mass literacy was only achieved during the nineteenth century, even in the advanced industrial economies of North America and north-western Europe. Thus for most of human history since the invention of writing there were more illiterate than literate people, and therefore more need in appropriate circumstances for those who could read to read aloud to those who could not. Before the invention of reading glasses around the turn of the fourteenth century, even those who had once been highly literate needed others to read to them once they became too long-sighted to read for themselves. The enduring tradition of Cuban cigar factor 'lectors', reading to rows of employees busily rolling cigars, is one of the best-known examples of people reading aloud to those who may (or may not) themselves be able to read, but whose hands were/are simply busy doing other things (Manguel, 1996; Tinajero, 2010). There are many other examples, though, including domestic scenes of reading aloud to family members doing needlework or shelling peas, and the seventeenth-century French veilleé or German Spinnstube: spinning circles of unmarried girls reading aloud to each other as 
they spun or knitted (Houston, 2002, pp. 103-104). Moreover, historians of the book (see for example Cavallo and Chartier, 1999; Vincent, 2000; Eliot and Rose, 2009) note that, even after the invention of the printing press and the expansion of the market for published texts, books remained expensive and often difficult to get hold of, especially before the spread of the lending library from the eighteenth century (Raven, 1996) and the arrival of cheap paperbacks in the twentieth. Reading aloud, then, was also a way to manage the common situation of many readers/listeners eager to access one book.

There are copious references in classical and medieval sources to oral reading, so much so that some scholars (see especially Balogh, 1927; Hendrickson, 1929) convinced themselves that silent reading was rare in the deep past, and that those who could read habitually did so aloud even when alone. This view has influenced and been repeated by many others. Manguel (1996, pp. 41-53), for example, asserts that reading aloud was the norm in the ancient world, and that 'well into the Middle Ages' this affected the way in which texts were written and presented. However, other classical scholars, in particular Knox (1968) and Gavrilov (1997), not only rebut the interpretation of many of the key texts frequently cited in favour of the rarity of silent reading in the deep past - especially the famous passage in Augustine's Confessions in which he describes seeing Ambrose bishop of Milan reading silently - but also show that there are about as many references to silent reading in classical and medieval sources as there are to oral reading. Gavrilov (1997, p. 59) reaches a balanced conclusion on the controversy: 'Knox argued that the basic thesis should be modified as follows. Reading to oneself was known to antiquity very early and was not felt to be something extraordinary. Nevertheless, because they loved the sonorities 
of language, people usually read aloud, especially with works of artistic literature.' A recent commentator (McCutcheon, 2015) appears to agree with this.

Conversely, others show reading-aloud practices persisting into the early modern period: Fox (1996, p. 132), for example, shows that authors read their books publicly in the seventeenth century, as Dickens famously did in the nineteenth, and Raven (1996, pp. 176, 199) suggests that, although there was certainly some silent reading in eighteenth-century England, reading aloud remained important in a number of contexts, including both public and private libraries. Yet even after this, as Williams (2017) explores in relation to the eighteenth-century British home, Reay (1991; 2004, pp. 137-139, 165-167, 170-171) discusses in a study of nineteenthcentury rural England, and the Reading Experience Database Project (2019) demonstrates powerfully in its diverse examples of both silent reading and reading aloud between 1450 and $1945,{ }^{1}$ oral and written forms of literacy co-existed within households and families. Just as some people read aloud today, so others in the past read silently as well as aloud.

It could be argued, however, that there has been a shift in the dominant cultural understanding of what 'reading' signifies: we suggest that this, in much of the contemporary Anglophone world at least, comprises silent, solitary activity. This conception of reading may be related to the type of texts that are read and promoted in educational settings. Radway (1994, p. 278) suggests that solitary reading is 'valorized as contemplative, meditative, and educational, and above all as serious'. Elster (2003, p. 685) contends that 'the dominant discourse of the modern era [foregrounds] a scientific and technological literacy', and with this, we argue, comes a conception of reading as individual, instrumental - and largely silent. Yet anecdotal evidence indicates that reading aloud occurs often and in numerous settings, both 
planned and unplanned, and in both social and solitary contexts. This is strongly supported by the new dataset used in this article; and yet the adult practice of oral reading is largely overlooked in both popular conceptions of reading (see Duncan, 2012; Duncan, 2015) and in the scholarly literature on contemporary literacy (see, for example, Pyrhönen and Kantola, 2018). Two books published in 2018, To read aloud (Dimitri, 2018) and The read aloud family (Mackenzie, 2018), stress their authors' views on the benefits of reading aloud. However, neither addresses to what extent adults across Britain may already be doing this - and why.

Ethnographic studies contain examples of adults reading aloud, from Besnier's work on Polynesian language use that identifies religious practices lying somewhere ‘between literacy and orality’ (Besnier, 1995, pp. 116-139), to Mace’s (2012) observations of Quaker meetings, and from Brice Heath's (1983) work in the Piedmont Carolinas to Barton and Hamilton's (1998) in Lancaster. Again, reading aloud for religious purposes features here, as does reading in the family circle. A number of Mass Observation directives relate to reading - examples are 'Viewing and Reading' (1983), 'Uses of Reading and Writing and Literacy Diaries' (1992), 'Reading' (1993), 'Mothers and Literacy' (1995) and 'Childhood Reading' (2003) and these provide the researcher with rich accounts of the role that reading plays and has played in people's lives. We learn little, however, from these sources about what was read aloud - as opposed to what was read silently, and why. The responses to these directives also tell us little about cultural practices which may not be popularly associated with the idea of 'reading': for example, the types of reading one may do in a café, at work, in an art gallery or, again, in a place of religious worship.

Finally, some studies of adult reading circles, book clubs or book groups contain examples of reading circles that choose to read aloud together (as well as 
those that do not), including insights into the power of sharing literary texts in this way (Davis, 2009; Duncan, 2012; Jones and Harvey, 2015). This work, together with Mass Observation and the ethnographic examples discussed above, provides us with glimpses of contemporary reading practices, while also demonstrating the need for a study that focuses specifically on adult reading aloud itself.

The one area on which more considerable popular and scholarly attention has focused is the practice of adults reading aloud to children. A recent survey by Nielsen Book Research showed a significant decline in the proportion of 'preschool' children who were read to on a daily basis by their parents (Flood, 2018). This built on earlier research from 2013, which showed that $69 \%$ of parents read to their children every day; and there is wide agreement that reading to children is beneficial to their development, and not just in the early years. For example, Cox Gurdon (2019), in The enchanted hour, stresses the importance of parents continuing to read to their children as they grow up. She does not, however, examine the degree to which many adults may already be reading books to older children or indeed to other adults. Reading aloud to children, though undoubtedly widespread and socially encouraged, is only one of many reading-aloud practices that are common in Britain and other countries, and which this article aims to illuminate.

\section{METHODOLOGY}

This article, then, seeks to uncover and explain the variety and extent of adult readingaloud practices in contemporary Britain. It is part of a larger project, 'Reading Aloud in Britain Today', which builds on an earlier pilot study (Duncan, 2015), to record and analyse contemporary reading aloud using multi-strand research design, including 
the national survey on which this article is based (see also Duncan, 2018; Duncan, 2019). ${ }^{2}$ The questionnaire built on earlier surveys of adult reading habits and preferences, few if any of which mention reading aloud (Scales and Rhee, 2001; Gallik, 1999; Kling, 1982; Sharon, 1973; Smith, 1990; Liu, 2005), as well as studies of reading aloud to children (Scholastic, 2018; YouGov, 2018). It contained 29 questions and was distributed electronically (with the option of a hard copy) in both English and Welsh. ${ }^{3}$ It elicited 529 usable responses.

Of these 529 respondents, $414(78.2 \%)$ are female and $112(21.2 \%)$ male, with a small proportion neither or not responding; around 6.5\% live in Wales, $12.2 \%$ in Scotland, and $40.8 \%$ in London and the south-east of England. ${ }^{4}$ Around half live in a city, just under a third in a town and just below a fifth in rural areas: this is approximately representative of the UK as a whole. ${ }^{5}$ In terms of age, $15.5 \%$ are 18 to $30,33.7 \%$ from 31 to $45,38.9 \%$ from 46 to 66 , and $11.7 \%$ are 67 and over. Just under a half report no religion; around $44 \%$ associate themselves with a form of Christianity and 3\% with Islam. Nearly a third consider themselves bi- or multi-lingual, with 59 languages other than English mentioned. Of 271 who completed an open question asking about their ethnic/cultural heritage, 162 describe themselves as some form of 'white', 12 use the word 'black' and 42 use other terms usually understood to come within BAME (Pakistani, African, Ethiopian, Latino, Turkish and Cantonese are examples). More than $95 \%$ of the whole sample described finding reading 'easy' or 'usually easy', as opposed to 'difficult' or 'usually difficult'. Around three-quarters have attended university; only two have had no compulsory schooling.

The sample, then, is in some ways unrepresentative, most obviously in two respects: a heavy preponderance of female and university-educated respondents. Moreover, as noted above, only a few respondents reported than they found reading 
difficult. Those who completed the questionnaire (entitled 'Everyday Reading') were aware that it was about reading (though not necessarily, initially, of the focus on oral reading), and this, combined with uses of technology to distribute project information and the questionnaire, almost certainly created a self-selecting sample of those confident in their own reading and in the use of technology. It is therefore important to note that our sample cannot be taken as representative of the wider British adult population in all respects. It does, however, capture many aspects of the diversity of contemporary British society, providing a broad insight into the oral reading practices of a range of adults living across England, Wales and Scotland today, and suggesting trends for examination in future studies.

\section{ADULT READING-ALOUD PRACTICES: GENERAL FINDINGS}

\section{[FIGURE 1 NEAR HERE]}

A key finding of the survey is that, simply but importantly, adult reading aloud is widespread: almost nobody never reads aloud, although the frequency and purposes of doing so vary significantly. Figure 1 shows the self-reported frequency of reading particular texts aloud. ${ }^{6}$ With the exception of religious texts, a considerable majority of respondents report reading all the named texts aloud sometimes, even if only occasionally. Almost all report at least some occasions of reading instructions or recipes aloud, and a similarly high proportion for shop signs and newspapers/magazines. In terms of very frequent reading, the most common type of text read aloud - with $22.1 \%$ and $38.4 \%$ of respondents reporting daily and frequent reading aloud - is social media posts, with newspapers/magazines, shop signs and instructions/recipes close behind. Emails and letters are read aloud daily by $19.5 \%$ of 
respondents, and often by $35.4 \%$. Children's books are the most commonly read texts on a daily basis, with $23.2 \%$ doing this. As shown in more detail below, the frequency of some practices reflect life circumstances and the lifecourse, with parents and grandparents predominating in the reading aloud of children's books. This is supported by the responses to an open question asking about whether participants' reading aloud practices have changed: of the 199 who replied to this, 87 wrote about changes to reading-aloud practices due to becoming grandparents or their children growing up.

A more surprising (perhaps) finding is in the proportions reading aloud books other than children's books, with $10.6 \%$ doing this daily and $27.1 \%$ frequently. This may be an atypical sample, but it suggests that many individuals and groups persist in a practice that Snow's character Paul Jago feared was dying out long ago. Shared oral literacy, even the time-consuming practice of reading of books to other adults, was not killed off by radio or television, and it appears to have survived the more recent digital transformation. This may lead us to wonder about the particular pleasures and purposes of reading aloud, and about the perceived benefits of shared literacy as opposed to - or as well as - other practices such as watching television as a couple or in a family group.

Participants were invited to comment on other texts they read aloud, and 134 people provided information about text types (for example, poems or menus) that are not explicitly included in the questionnaire. Here some of the less frequently noted activities give us a sense of the variety of things that are read aloud. For example, the (one) person who notes reading aloud amusing graffiti from toilet doors and walls, the (again just one) person who reads bus numbers and car number plates aloud, the person who reads out plant labels, the three who read from museum or gallery 
placards, the four who read from food packaging, or six from menus. Meanwhile, the prevalence of some practices is also notable: there were also 20 mentions of reading plays or scripts and 38 of poems. When asked, in a different open question, about the text type they read aloud most often, the findings echo those in Figure 1: as many as 140 respondents read to children, 88 mention social media and/or text messages, 79 write about 'news' and 55 about recipes/instructions.

These findings are striking, and they are strengthened by examining some of the practices in relation to each other. Almost all of our respondents read something aloud daily or frequently: 482 (90.9\% of the total) read something aloud at least monthly, and 275 (51.9\%) report reading at least one type of document or text aloud daily. Conversely, only 32 respondents $(6.0 \%$ of the total) report never or only occasionally reading anything aloud, and just 17 of these $(2.6 \%)$ answered 'never' to all the questions. These noteworthy figures may be partly an artefact of the sample, but they highlight adult engagement in a wide range of reading-aloud practices, and suggest that oral reading is certainly more widespread and diverse than is often acknowledged.

There are some differences between men and women, although the overall patterns are not dissimilar. In the case of every text type, men are less likely to read aloud daily or frequently, and more likely to answer 'never'. Table 1 makes these differences clear: almost two-thirds $(66.1 \%)$ of men in the sample never read religious texts aloud, while only $1.9 \%$ read instructions or recipes aloud on a daily basis. These proportions probably reflect higher levels of religious observance, and greater participation in cooking, among women. Of the 32 respondents who read aloud only occasionally or never, exactly half are male, representing $14.3 \%$ of the sample of men, and the other 16 female, or $3.9 \%$ of the women who responded to the survey; 
and of the 14 who claim never to read aloud at all, 11 are male, or $9.8 \%$ of the men in the sample. Yet a clear majority of men in the sample read at least something aloud monthly or more often - 91 or $81.3 \%$ - and nearly half (45 or $40.2 \%$ ) do so every day.

\section{[TABLES 1 AND 2 NEAR HERE]}

There are some predictable differences between the age groups covered by the survey, although some practices seem quite similar in extent between the different cohorts. Table 2 shows little variation in the proportions reading newspapers or magazines aloud, for example, or emails and letters, although those in the oldest age group are more likely to report never reading newspapers/magazines, letters and emails, shop signs, instructions/recipes and social media posts aloud. On the other hand, they were slightly more likely to read religious texts, reflecting higher levels of religious observance among older people. The frequency of reading children's books aloud reflects the lifecourse, with those aged 31 to 45 most likely to read these on a daily basis, and those in the older age groups more likely to read them often, but not daily. Many of those in the 31 to 45 age group may well be parents of young children, while non-co-resident grandparents will be in the older age groups. Those aged 30 and below are least likely to read children's books aloud. Conversely, they are the most likely to read social media posts aloud on a daily basis; however, the proportion reading these aloud often or daily is actually slightly higher among the 46 to 66 age group. Among those aged 67 and over reading social media posts aloud is relative uncommon, with nearly half reporting that they never do this, and a further $9.1 \%$ doing so only occasionally. The age spread of those who read aloud only occasionally 
is roughly in line with that of the sample as a whole, as is that of the small group who never read aloud at all. ${ }^{7}$

\section{[TABLE 3 NEAR HERE]}

We also asked why people read aloud, offering eleven options (see Table 3) and inviting free-text responses. The tabulated results show that, across the sample as a whole, among both women and men and all age groups, the most popular answer is 'to share what I have read with someone', which is perhaps not surprising, although a majority in all groups also use reading aloud to memorise and learn. Indeed, more than half in most age groups - and more than half of women and $44.6 \%$ of men report reading aloud to learn or read another language. This could range from sustained study to casual reading of signs while travelling abroad: one respondent noted that she reads aloud '[o]n holiday, reading signs like "EXIT" etc., or a menu'. Women and those in the youngest age groups are most likely to read aloud to help or serve another person: such help or service can range from reading to a partiallysighted relative to reading something for someone who has forgotten their glasses. As is the case elsewhere, responses under this heading are likely to reflect the lifecourse and the distribution of caring responsibilities. Reading aloud for religious purposes becomes a little more common with age. In terms of gender, all of these reasons for reading aloud are given more often by women than men, but the rank order is much the same for both. Strikingly, Table 3 shows that $58.5 \%$ of women in the sample, and $46.4 \%$ of men, comprising $56.0 \%$ of the total, read aloud 'because I enjoy it'.

Before being faced with these eleven options, participants were asked to write down, in an open question, why they read aloud. This invitation was taken up by 397 
participants, with the most popular response being a version of 'to better understand a text' (84 mentions), with 'sharing information' mentioned 80 times. These initial responses are notable for the sheer range of purposes expressed: some describe the pleasures of simply hearing voices (including one's own), while others use reading aloud when alone for memorising information or to compose text. Some read aloud to learn, practise and enjoy different languages, and others to settle, teach, motivate and interact with their children. Some delight in the sounds of words and phrases as they say and hear them, and others find it a good way to be with other people, whether in different sorts of groups or in the intimacy of a couple. These responses are notable not only for their range, but also for the nuance they present. For example, many freetext responses concern 'sharing' texts with others, but with quite different conceptualisations of the value or need for sharing. 'Wanting someone to hear' the logistical information contained in a letter or email is quite different from richer explanations such as '[y]ou can share something you love with other people' or 'to pass on information and start a conversation'. Or, to take another example: 'when reading a funny or interesting line in an article or book I can emphasise certain words or phrases for effect and share the humour (or horror!) that I find in it'. Similarly, participants explained the well-known practice of reading aloud to children in quite different terms, ranging from 'reading aloud to my grandchildren because they are too young to identify and read the words yet', to 'with my child, there's a connection when we read together', to 'it feels fabulous, enhances the meaning, brings the text to life and is an intimate activity'. Many participants emphasise the intimacy of the voice and physical closeness central to reading aloud with a child or another adult, while just as many others (and some of the same) stress the educational benefits of enhancing vocabulary, acquiring new pieces of information and developing literacy. 
[FIGURE 2 NEAR HERE]

This diversity of purpose is related to the different formations in which adults read aloud. Table 3 suggests that reading aloud is both a shared and a solitary practice, and this is borne out by the responses to a question which asked directly about this aspect of oral reading. Figure 2 shows that more people read out loud to only one other person than in any other formation, with reading to a group next and reading aloud alone a little less common, though still done daily or frequently by almost half the sample. Only $9.8 \%$ say that they never read aloud to one other person, again emphasising the ubiquity of reading aloud in these personal and social lives. Reading to a group may be done in families and is also common in workplace situations. Religious practices - and perhaps other occasions involving group or individual singing, recitation or chanting - may account for the relatively high proportions who read aloud in unison in groups, with 17 individuals claiming to do this every day, and almost a quarter of the total doing it daily or often.

The 358 free-text comments on this question reveal further information about the life domains in which reading aloud occurs. Two-hundred and thirty-five participants write of reading aloud in home or family settings, including to partners and children, and even in some cases to cats and dogs. There are 151 examples of reading aloud in workplaces, 48 with friends, 44 in performance or artistic settings and 21 in religious contexts. Typical comments on this topic include: 'I am a librarian so sometimes read aloud to a group; emails etc[.] to relay information to staff'; 'I read aloud children's books to my daughter and textbooks to my class. I used to volunteer and read letters and information to a blind couple'; 'I read aloud from religious texts 
to my church group. I read online articles aloud to my friend. I read books or instructions to myself to help me understand things better'; '[w]e read aloud from the Bible in church - one reads and everyone follows'; 'I am a member of a book club and we often read relevant passages out to the group. When attending marriage ceremonies I read from a script and sometimes guests read out poems'; and '[I r ] ead particular excerpts of books or newspaper articles to my boyfriend if I find them particularly interesting or think that he might enjoy them too'. Younger people often report reading emails and news items to partners, friends or 'workmates': one woman in her 30s notes that '[o]bviously if I see something amusing online ([US President Donald] Trump has proved fruitful news fodder for sharing with partner, in office, etc).' Of the 82 respondents in the ' 30 and below' age group, 64 wrote a comment here, and of these 29 explicitly mention reading aloud to their partner or spouse.

\section{[TABLE 4 NEAR HERE]}

It is almost axiomatic that new media influence literacy practices, especially among younger people, and there is now a large literature on the nature and impact of 'digital literacies' (see for example Burnett et al., 2014; Gillen, 2014). We asked our respondents whether they read aloud from screens, and 412 (77.9\%) replied that they do, with only 109 (20.6\%) saying that they did not. The results of this question are broken down in Table 4. Members of the oldest age group are less likely to read aloud from screens than the youngest, but a majority do so in all age groups, and among both women and men, though with an even greater preponderance among women. Of the 412 respondents who wrote that they do read from screens, 371 gave additional comments, revealing a mixture of texts (social media, emails, poems), reasons 
(understanding, sharing) and devices (phones, Kindles, computers); some suggested that they do most of their reading aloud (and reading more generally) from screens, including religious texts and their own writing, while others read aloud from screens only those texts that appear solely on screens (emails, social media posts, text messages). These additional comments also show that, in the case of the latter types of text, most are read from phones, whereas texts that appear in various formats are more often read from computer screens. ${ }^{8}$

In the rapidly changing environment of digital media and devices, further change is likely, and more research will reveal evolving practices. Having said this, there is no direct evidence from this survey that people read aloud more, or more frequently, due to the changing digital landscape: when asked whether and why their reading aloud practices have changed, 194 respondents commented, with most of these citing life changes, and very few mentioning on technology in this context. However, the question warrants further research, given the ubiquity of digital technology use among both our sample and the population as a whole. It is certainly quite clear that social media and other digital technologies create some new, and perhaps unanticipated, settings in which fairly casual forms of reading aloud might occur; in this respect they may either supplant or complement existing media.

We also asked whether participants read aloud in more than one language: just under half -232 or $43.9 \%$ of the total number of respondents - said that they do, compared with just under a third of the sample describing themselves as bi- or multilingual. A number of respondents, as noted above and in Table 3, use reading aloud to help them learn or practise another language. It is clear, then, that reading aloud is common in both English and other languages spoken in Britain, and also for language-learning purposes. Participants read the news, social media posts, books and 
sometimes instructions and recipes, in a range of languages: either because these are the languages they are most comfortable reading or the texts they have easiest access to, or in some cases in order to maintain individual or familial engagement with a heritage language. In total, 46 languages are explicitly mentioned in this context, including some 'dead' languages such as Old Norse and Middle English, which are read aloud for both pleasure and education; and some such as Quranic Arabic and Hebrew for religious purposes. This can sometimes involve reading a language one does not use in daily spoken interaction (see for example Baker, 1993; Herbert and Robinson, 2001).

\section{[TABLE 5 NEAR HERE]}

Another series of questions asked about listening to others reading aloud. Table 5 breaks down the frequency of hearing particular text types read aloud by gender: these are the same text types as in Table 1, but with the addition of audiobooks and books read on the radio. In general, there seems to be a slightly lower incidence of hearing things read than of reading them aloud oneself, and this is true among both men and women, for whom the proportion answering 'never' is higher for all but one of the categories, i.e. religious texts, in Table 5 than in Table 1 . The same pattern emerges if the categories 'never' and 'occasionally' are added together. These proportions in part may reflect the fact, shown in Figure 2, that a considerable proportion of reading aloud is done alone. It is also possible that respondents are less likely to notice the various kinds of reading aloud that they hear on a frequent basis, as we will discuss in more detail below, although only nine respondents - three women and six men - reported that they never heard any of the text types read aloud. 
For each text type, the proportion of men who never hear others reading aloud is higher than the proportion of women.

Listening to others read aloud can also be a solitary activity, with a number of respondents mentioning that they listen to reading on the radio or to podcasts, either alone or in company. (Some of these broadcasts may not, strictly speaking, involve reading aloud, but of course many do.) Table 5 shows that rather more women in the sample listen to audiobooks or books read on the radio daily (16.4\%) or often (27.9\%) than men (12.3\% and $21.7 \%$ respectively). Indeed, female respondents are more likely to hear audiobooks or books on the radio daily than any other text type - although, conversely, a third of women and more than $40 \%$ of men report never hearing them. Interestingly, listening to audiobooks or books on the radio is somewhat more widespread among the 23 to 30 age group, of whom nearly a half (47.9\%) in our sample report doing this daily or often, compared with $40.2 \%$ of those aged 31 to 45 and $43.7 \%$ in the 46 to 66 group, and just over a third of those aged 67 and over.

These findings can be compared with the statistics released by the Publishers' Association for 'Love Audio' week in June 2018 (Cowdrey, 2018), which suggests that men aged 18-44 are the 'key demographic' in the recent increase in audiobook sales. Taking the comparable age range in our sample - 18 to 45 - we see that a higher proportion of men (21.4\% versus $13.7 \%$ of women) report daily listening, whereas 28.3 of women and $14.3 \%$ of men listen often. The proportions never listening were about the same, just below $40 \%$. It is possible that, across the whole sample, more women listened to the radio and more men to audiobooks, but this can only be speculation. Daily listening to audiobooks may possibly reflect commuting habits, but it is difficult to judge from our survey, as only two respondents mentioned this explicitly. The younger listeners may be using newer technologies to access these 
resources - from our free-text responses, the older age groups predominate among those mentioning the radio and younger people among those who mention podcasts but it is clear that listening to broadcast and recorded voices reading aloud remains a widespread and regular practice among this sample. It is worth noting that, as might be expected, a majority of those who listen to recorded readings-aloud often or daily do so only alone (140 out of 261 in the sample), but 101 do so both alone and in the company of someone else, and the other 20 only with someone else.

As with reading aloud itself, workplaces and religious settings are mentioned in the context of listening to others reading aloud, and some respondents note that they hear children themselves reading children's books - either their own children or in their workplace (for example, a school or library). New technologies bring new ways to hear the read-aloud voice: as well as podcasts, four respondents mention hearing route directions on a phone or 'satnav'. As with reading aloud, hearing others read involves a mixture of longstanding activities that are widely commented upon 'I listen to my husband reading to my son' or 'I listen to prayers and the reading of the Torah in Hebrew when I attend synagogue' - and new literacy practices that are still evolving. (A satnav voice, it could be argued, is not, strictly speaking, an example of reading aloud at all.) When asked whether they read aloud more than they listen to others reading aloud, $33.3 \%$ of our sample said that they do, whereas $36.5 \%$ said the opposite, that they listen to others more than they read aloud themselves. In many settings, it can be hard to separate reading aloud and listening: they often occur together. As one participant commented, '[r] eading and listening are integral to each other[,] though to listen well in some circumstances is more difficult than reading aloud.' 


\section{DISCUSSION: THE ‘COMMON’, VISIBILITY AND IDENTITY}

The findings of our study identify a number of features of adult reading-aloud practices. They suggest that reading aloud happens in a number of different ways and for different purposes, across contexts and life domains, and that it has a significant relationship with aspects of the lifecourse and with identity formation and performance. This is not to suggest that reading aloud is more widespread than reading silently: indeed, only 10 respondents agree with the statement 'I read aloud more than I read silently'. However, we have shown that very few adults in our sample do not read aloud at all, that most read more aloud than they initially realised, many read aloud a great deal, and that some - in fact more than half of our sample read aloud because they enjoy doing it. These findings suggest that more notice should be taken in literacy research of adult reading-aloud practices, including areas that are largely overlooked, such as the quotidian activities of reading text messages and social media posts, the use of reading aloud when completely alone, and the perhaps surprisingly common practice of adults reading books to each other, all of which, with many others, our survey highlights as 'common' practices in the lives of the participants.

When we describe a social practice as being common or 'everyday', we can mean different things. Some things are read often or daily by a majority of respondents, including newspapers and magazines, social media posts and shop signs, road signs and posters (see Figure 1). Even texts which a majority of respondents do not read aloud, or perhaps even encounter, are read aloud frequently by a significant minority, the obvious example being texts read by members of religious congregations. For some individuals, the daily reading of texts is part of their work: 
teachers, poets, actors, ministers of religion and others identified themselves in the survey. Some other professions involve structured reading aloud: for example, one respondent noted '[i]n my work as a psychotherapist I read prepared scripts to my clients all the time.' A similar point can be made about a significant minority who read aloud as part of their leisure or cultural lives: our sample included a number of individuals who regularly read poetry to larger or smaller audiences as well as those who read their writing to creative writing groups.

Another aspect of 'commonness' concerns practices that most individuals may do at some point in their lives, but not regularly or frequently, as part of rituals that are socially widespread: for example, three respondents mentioned reading aloud at funeral services and another three at weddings. These are not done often by any one individual (except by professionals such as ministers and registrars), but they are socially widespread; and they can involve a large number of hearers. Finally, there are practices that become common to people at certain points in the lifecourse, the most obvious being reading to children (see above and Table 2 for the variations in the frequency of this practice by age). The commonness of a practice, then, can be understood in terms of social pervasiveness - funerals and weddings take place daily, but most of us attend them relatively infrequently - or in terms of frequency within individual lives, as well as patterns across the lifecourse.

Another way we can understand the 'commonness' - or not - of a literacy practice is to explore notions of visibility, that is, how much practices are noticed or talked about within a wider culture or context, or even by the readers themselves. An Internet search for 'reading aloud' will generate a plethora of sites that discuss the importance of reading to children, and the cultural approbation of the practice is such that parents who do not read to their children are criticised in the media (Morton, 
2018). By contrast, other adult reading-aloud practices, such as reading aloud from newspapers or social media to friends or family, or reading aloud alone as part of a writing or study process, are less 'visible' - less often mentioned, written about less, and often not noticed even by those who do it.

Several aspects of visibility are highlighted by our data. The first is that visibility is related to what we might - no doubt problematically - call the public and private spheres. Practices that occur in the public sphere, such as poetry performances, are likely to be more visible culturally than those occurring in the home. Such public occurrences of reading aloud are more easily noticed, even by nonparticipants, than partners reading to each other, the solitary reader helping himself get through a difficult text, or the volunteer reading to her blind neighbour. Reading aloud that happens in the home, perhaps in bed, as some respondents note, is particularly hidden from public view, and usually involves only one or two people. In our survey (see Table 1), a third of male respondents and almost $40 \%$ of women report frequent or daily reading aloud of books other than children's books, not to mention other practices that are even more common in private family settings, such as reading newspaper and magazine articles, emails and social media posts. One respondent claimed that reading aloud is '[b]est done in the bath': though whether she does this alone or with an audience is not clear (she does claim never to read children's books). Another explained that 'I live alone - maybe the sound of my own voice breaks the silence. I read to my imaginary friends ... It does help me to concentrate.' The home, then, is a place of private and generally less visible readingaloud practices, with one notable exception: parents' reading to children enters the public sphere of reading aloud probably because it is explicitly encouraged by the educational professions and, as noted above, in the popular media. Family literacy 
research (Carpentieri et al., 2011) repeatedly emphasises the importance of the practice within the home as well as in schools and libraries, and as such a domestic activity becomes a feature of widespread public discussion.

The visibility of a practice is also highly contextual: what happens in one life domain or setting may be visible there but not in others. For example, the readingaloud practices of healthcare professionals may be widely noticed within the relevant settings but not elsewhere: many people would be unaware that therapy scripts and medical notes are routinely read aloud. Things that are part of daily life for certain groups within the population are largely absent from the lives of others. There is also a lifecourse dimension to this: we may find that we read aloud to older relatives, which we are more likely to do, and notice, at certain junctures in the lifecourse than at others.

Similarly, as Elster (2003) has argued, some literacy practices, including forms of reading aloud, are important within a religious context but largely overlooked in both the academic literature and also in mainstream literacy teaching. From the point of view of literacy education, perhaps the most striking aspect of the relative cultural visibility of literacy practices is this invisibility of forms of adult reading aloud within educational conceptualisations of reading. For example, both the (English) Adult Literacy Core Curriculum (Excellence Gateway, n.d.) and the (Canadian) Ontario Adult Literacy Curriculum Framework (Ontario Ministry of Training, Colleges and Universities, 2015) break 'reading' down into various elements, but none relates to the orality of reading. In other words, within these curricula, reading means silent reading. Reading aloud may (sometimes) be used as a tool to develop 'reading', but this 'reading' is conceptualised as a silent, individual process, acknowledging skills of decoding, comprehension and inference (to take a 
few examples), but overlooking skills related to the communication of meaning or other uses of the voice. As noted above, within both adult literacy and language teaching attention is focused on the effectiveness (or otherwise) of reading aloud as a classroom tool to develop language or literacy, for emphasis or to engage learners, but with little or no recognition of reading aloud outside the classroom (Duncan, 2008; Duncan, 2012). Where 'real-life' practices are mentioned, they tend to be limited. In 2009, the (US) National Institute for Literacy discussion list hosted an online debate on reading aloud in the classroom, with one practitioner arguing '[e]xcept for students who want to be radio announcers or preachers, I'm not sure what it accomplishes' (National Institute for Literacy, 2009). This lack of visibility of reading-aloud practices in educational contexts is striking, not only for the limited view of reading that it betrays, but also in the context of the relationship between literacy practices and constructions of identity.

Literacy practices in general, and - we argue - reading aloud in particular, can play an important role in the construction and maintenance of individual and group identities, at all levels. In identifying the domains in which they read aloud, our respondents both implicitly and explicitly relate the practice to their personal relationships, professional self-understanding, religious beliefs and other aspects of cultural belonging. Some use reading aloud to help perform their occupational and political identity - '[a]s a local councilor [sic], I often read letters and emails that people from my ward have written to me aloud during council meetings'; '[w]hen I worked as a Teaching Assistant and as a Sessional Instructor I would to varying degrees read aloud to my classes' - and others to help them do a better job: 'I work as an editor in book publishing so I often read sections of the books I am working on aloud ... in order to edit and proofread the content'. 
Participants also remember, as children, reading aloud and reciting text as an aspect of the performance of their identity as family members: '[w] hen I was growing up, my family used to read or recite poems to one another. My brothers and I would each learn a poem by heart to recite to my father for his birthday each year.' Many respondents describe reading aloud to children explicitly as an activity that strengthens family relationships and one's identity as a parent. As one comments, '[r] eading bedtime stories to my children has been one of the most important and rewarding aspects of parenting to me.' This view of reading with children is reflected in the 'Storybook Dads' initiative, which allows parents in prison to record themselves reading books to share with, and thus maintain a certain connection with, their children (Storybook Dads, 2019). This is a particularly poignant example of the power of the individual human voice in reading aloud.

Religious, cultural and linguistic communities may also be sustained by reading aloud. Some respondents mention reading aloud in synagogues, while a number of Quakers in the sample emphasise the importance of reading aloud in both worship and business meetings. Reading aloud, even alone, can help with religious engagement: one Muslim notes that 'I prefer reading out loud otherwise I sometimes feel I am just reciting it [the Quran] subconsciously and my mind drifts, rather than a conscious engagement'. Keeping in touch with other languages - perhaps connected to cultural heritage or scholarship - is another reason for reading aloud: one woman reports that, while English is her 'main language', she hears Sanskrit being read at 'workshops', and listens to news in Hindi and Punjabi. Other, more complex feelings of belonging are also served by reading aloud: one woman, a native English speaker who lived in France for five years, reads French aloud 'because I like the sound and I miss speaking French on a daily basis'. For some, reading aloud is used to support 
gender identities: one respondent runs a group where women 'share stories and poems ... to help women to relax and take time out of their day, to rediscover the joy of listening'. Other, less well-known, social groups are also supported in this way: one respondent reads fan fiction aloud, 'because it allows me to be part of the fannish community'.

There are many other reasons why people read aloud, arguably more narrowly instrumental in some cases, and these can overlap with the bigger issues of identity formation. They are, though, no less important, and indeed many people express the pleasures and satisfaction that reading aloud can bring, even if its main purpose is to achieve a practical end. Reading aloud may help someone to write a better email at work, or to help a learner develop her French pronunciation, or because 'it helps me to concentrate and understand'. Neither reading nor writing are always silent practices, and reading aloud can help with composition: we both found when composing this article together that we read aloud as we write much more than we were previously aware.

Thus we return to the quotidian uses of reading aloud with which we began this section, and the prevalence of which is perhaps the most important finding of this article. While one is unlikely to overlook the longer, and often planned, practices of reading a whole book to a child or reciting a prayer, many instances of reading aloud are brief, unplanned and sometimes unnoticed, such as the spontaneous activities of reading recipes, instructions and social media posts to others. These shorter 'snippets' are not only less culturally visible, but are often not noticed even by the person doing the reading: as one of our respondents notes, 'I did not realize how much we read aloud. I probably have not included all the examples of when I read aloud, as we do this without thinking most of the time.' 


\section{CONCLUSION}

This type of comment appears a number of times in responses to our survey, and also elsewhere in the larger research project, 'Reading Aloud in Britain Today', of which it forms a part (see for example, Duncan, 2018, Duncan, 2019). It perhaps helps to explain why forms of reading aloud have not usually had the prominence that they may warrant in either the academic literature on literacy or educational understandings of reading. Across our sample, reading-aloud practices are ubiquitous and remarkably varied; they are sometimes visible, and sometimes invisible, but very often important to personal or cultural identities. This importance is reinforced by other elements of the larger project, some of which will enable the particular analysis of groups that are under-represented in the sample here, notably men and those with less formal education (see for example British Library, 2018).

In this way, our research contributes both to adult literacy studies and to the ethnography of reading. Thus, whereas much of the literature proposes a historic shift from reading as oral and communal to reading as silent and individual, our findings show that reading is (for at least some people) all of these things. Our analysis suggests ways that we can understand or unpack the 'commonness' and visibility of an 'everyday' literacy practice, exploring notions of frequency within individual lives, changes over the lifecourse, social pervasiveness and contextual visibility. Although this is not primarily an historical study, our findings do suggest that the extent of change over time in oral reading habits might have been overplayed, to an extent at least, in the literature. Paul Jago's lament for a lost reading practice seems to have been premature, to say the least, and our evidence suggests that, despite the growth of 
digital technologies, many adults find the time to read books to each other, and to take pleasure in doing so - and of course, these books themselves may well be in newer digital formats.

This article is also a call for future studies building on this work, examining the forms of reading aloud performed, used and enjoyed by adults of different educational backgrounds, in different countries and contexts, for different purposes and with different meanings, in different languages and with different uses of technology. In our wider research project, analysis of interview and Mass Observation data is also opening up examinations of what we could call 'in-between' practices where forms of reading aloud are intertwined with paraphrasing, spontaneous oral language and/or recitation as part of, for example, presentations, teaching, religious reading and even the reading of menus or posters. These complex interplays between the oral and the written are also potentially fruitful areas for future research. Finally, we argue that it is important for teachers, teacher-educators, curriculum developers and policy-makers to take note that adult reading is so much more than a silent process of decoding text. Educational conceptualisations of reading, curricula and forms of assessment all need to acknowledge the breath and diversity of adult reading practices - visible and less visible, solitary and shared, silent and aloud.

\section{DISCLOSURE STATEMENT}

No potential conflict of interest was reported by the authors.

\section{FUNDING}

This article is based on research undertaken for the project 'Reading Aloud in Britain Today', funded by the Arts and Humanities Research Council, award number AH/P0077937/1. 


\section{ACKNOWLEDGEMENTS}

We are grateful to Greg Brooks for comments on an earlier draft, and to JD

Carpentieri and Charlie Owen for advice on the construction of the questionnaire.

\section{NOTES}

${ }^{1}$ In one example from the RED, an eighteenth-century daughter of a diplomat 'listened to her husband and step-son reading aloud the newspaper and Sutherland's "Tour of Constantinople"'.

${ }^{2}$ The source for all tables and figures is the questionnaire undertaken for this project. The other research instruments include a Mass Observation project directive - which received responses from 160 correspondents -49 in-depth interviews, and the collection of 44 audio-recordings of practices deposited in the British Library (2018). ${ }^{3}$ The questionnaire was distributed via the RaPAL Regional Advocates network, and two of the 'Reading Aloud in Britain Today' project partners, The Reading Agency (UK) and the Learning and Work Institute (England and Wales), with combined national networks including the Society of Chief Librarians, Scottish Library and Information Council, the Book Trust and Scottish Book Trust, Unionlearn, UNISON, community centres, and groups working with older people and the homeless. The questionnaire was also disseminated through the project website, professional networks and social media. The choice was made to use an online survey following positive feedback from adults from a range of educational and social backgrounds in the initial phase of piloting, along feedback from project partners that an online survey could facilitate greater regional participation and maximise project resources. Participants were offered the opportunity of doing the survey in hard copy, and 46 of these appear in the sample. It is possible, however, that the choice of an online survey may have exacerbated the over-representation of university-educated participants in the sample. The interview phase of the wider research project aimed to work against this bias and to ensure the inclusion both of participants with less formal education and of those who do not use digital technology. A PDF version of the questionnaire is available on the project website: https://www.ucl.ac.uk/ioe/research/projects/readingaloud-britain-today

${ }^{4}$ These figures for location are based on the proportion of those who reported one (n $=507)$. The figures for religion are based on a summary of free-text responses, and should be considered approximate.

${ }^{5}$ The intercensal population estimates (for England) have a figure of $17 \%$ living in rural areas (DEFRA, 2016); this would be a little higher if the whole UK were considered. In our sample, the proportion is $18.5 \%$.

6 'Occasionally' includes those reading the text type aloud less often than once a year or only once or twice a year, while 'often' includes those reading the text type aloud at least once a week or once a month. In the questionnaire, after feedback from the two piloting phases, 'daily' was rephrased as 'about every day or two'. Similarly, 'weekly' was phrased as 'about once a week', 'monthly' as 'about once a month', and so on. 
${ }^{7}$ There are also some differences between those with and those without a university education, and between those living in urban and rural areas. The differences, however, are not large, although both aspects of reading aloud could potentially benefit from further research.

Of 493 individuals in the sample who reported their level of education, 391 had been university-educated and 102 had not. For all of the text types discussed in the body of the article, non-university-educated respondents were more likely to report reading aloud daily: in the most striking case - emails and letters - the proportions are $39.8 \%$ versus $13.7 \%$. However, when the 'often' and 'daily' categories are added together, the differences are reduced: thus, for example, for emails and letters the proportions are $60.7 \%$ versus $50.4 \%$. The proportions for the non-university-educated are still higher in all categories, but less significantly so for the most part. The proportions who never read the given text types aloud are mostly very similar. A somewhat higher proportion of university-educated respondents ( $55.0 \%$ versus $40.2 \%$ ) reported that they 'like reading aloud'. The key finding of this study is that reading aloud is ubiquitous across the lifecourse and throughout the population, and the limited data on education bear this out: reading aloud appears to be widespread among those both with and without advanced academic education.

Looking at rural and urban areas tells a similar story: there are some differences, but the overall patterns are similar. For each text type except children's books, those in urban areas were more likely than those in the countryside to report reading aloud often or daily, in some cases considerably so (for example, $61.3 \%$ versus $51.3 \%$ for newspapers/magazines and $56.7 \%$ versus $44.7 \%$ for emails and letters). Some of the differences, such as the higher proportion reading children's books aloud in rural areas and the lower proportion reading social media posts aloud, reflect the age structure of the samples (more than two-thirds of our rural respondents were aged 46 and over, compared with less than half the urban sample, and only $3.1 \%$ were under 30, compared with almost a fifth of those living in towns and cities). The lower proportions reading shop signs and books other than children's books aloud in rural areas may reflect social isolation, but more data would be require to draw a less speculative conclusion.

${ }^{8}$ When producing the questionnaire, we considered asking for more detail on digital practices but our two phases of piloting made it clear that we needed to reduce rather than increase the number of questions and so aimed to focus more on frequency and purposes of reading aloud (using any materials, paper or screen) and leave a more detailed examination of digital technologies for a future study. 


\section{REFERENCES}

Baker, J. M. (1993) The presence of the name: Reading scripture in an Indonesian village. In Boyarin, Ethnography of Reading.

Balogh, J. (1927) 'Voces Paginarum': Beiträge zur Geschichte des lautes Lesens and Schriebens. Philologus, 82 (1-4), 84-109.

Barton, D. and Hamilton, M. (1998) Local Literacies: Reading and Writing in One Community (London: Routledge).

Besnier, N. (1995) Literacy, Emotion and Authority: Reading and Writing on a Polynesian Atoll (Cambridge: Cambridge University Press).

Boyarin, J. (Ed) (1993). The Ethnography of Reading (Berkeley: University of California Press).

Brice Heath, S. (1983) Ways with Words: Language, Life and Work in Communities and Classrooms (Cambridge: Cambridge University Press).

Brice Heath, S. (2012) Words at Work and Play: Three Decades in Family and Community Life (Cambridge: Cambridge University Press).

British Library (2018) Reading Aloud in Britain Today: Project Recordings (Sound and Moving Image Catalogue, shelfmark C1765).

Burnett, C., Davies, J., Merchant, G. and Rowsell, J. (2014) New Literacies around the Globe (New York: Routledge).

Carpentieri, J., Fairfax-Cholmeley, K., Litster, J. and Vorhaus, J. (2011) Family Literacy in Europe: Using Parental Support Initiatives to Enhance Early Literacy Development (London: NRDC, Institute of Education).

Cavallo, G. and Chartier, R. (1999) Introduction (Trans. L.G Cochrane). In G. Cavallo and R. Chartier (Eds), A History of Reading in the West (Cambridge: Polity). 
Cox Gurdon, M. (2019) The Enchanted Hour: The Miraculous Power of Reading Aloud in the Age of Distraction (London: Piatkus).

Cowdrey, K. (2018) Audiobook downloads rose 22\% last year, PA stats show. The Bookseller, online, 11 June: https://www.thebookseller.com/news/audiobook-saleshit-record-31m-pa-stats-reveal-love-audio-week-802446 (accessed 29 March 2019).

Davis, P. (2009). Interview: talk to me. Phil Davis in conversation with David Fearnley. The Reader, 34, 31-38.

DEFRA (Department for Environment, Food and Rural Affairs) (2016) Official Statistics: Rural Population 2014/15:

https://www.gov.uk/government/publications/rural-population-and-

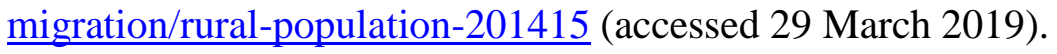

Dimitri, F. (2018) To Read Aloud: A Literary Toolkit for Wellbeing (London: Head of Zeus).

Duncan, S. (2008) What are we doing when we read aloud? Reflect, 11, 24

Duncan, S. (2012) Reading Circles, Novels and Adult Reading Development (London: Continuum).

Duncan, S. (2015) Reading aloud in Lewisham: an exploration of adult reading-aloud practices. Literacy, 49 (2), 84-90.

Duncan, S. (2018) Lend me your ears: Mass Observing contemporary adult reading aloud practices. Changing English, 25 (4), 410-425.

Duncan S. (2019 forthcoming) Reading Aloud in Britain Today: an overview and implications. Research and Practice in Adult Literacies, Journal, 97.

Duncan, S. and Paran, A. (2018) Negotiating the challenges of reading literature: Teachers reporting on their practice. In J. Bland (Ed), Using Literature in English 
Language Education: Challenging Reading for 8-18 Year Olds (London:

Bloomsbury).

Eliot, S. and Rose, J. (Eds) (2009) A Companion to the History of the Book (London: Wiley).

Elster, C. (2003) Authority, performance, and interpretation in religious reading: critical issues of intercultural communication and multiple literacies. Journal of Literacy Research, 35 (1): 663-692.

Excellence Gateway (n.d.). Adult Literacy Core Curriculum: http://www.excellencegateway.org.uk/node/1515 (accessed 2 May 2018).

Flood, A. (2018) Big decline in number of parents reading daily to toddlers. Guardian, 22 February, 14.

Fox, A. (1996) Popular verses and their readership in the early seventeenth century. In Raven et al., Practice and Representation of Reading.

Gallik, J. D. (1999). Do they read for pleasure? Recreational reading habits of college students. Journal of Adolescent \& Adult Literacy, 42 (6), 480-488.

Gavrilov, A. K. (1997) Techniques of reading in classical antiquity. Classical Quarterly, 47 (1), 56-73.

Gebre, A. H., Rogers, A., Street, B. and Openjuru, G. (2009) Everyday Literacies in Africa: Ethnographic Studies of Literacy and Numeracy Practices in Ethiopia (Kampala: Fountain Publishers).

Gillen, J. (2014) Digital Literacies (London: Routledge).

Hendrickson, G. L. (1929) Ancient reading. Classical Journal, 25 (3), 182-196.

Herbert, P. and Robinson, C. (2001). Another language, another literacy? In B. V. Street (Ed), Literacy and Development: Ethnographic Perspectives (London: Routledge). 
Houston, R. A. (2002) Literacy in Early Modern Europe: Culture and Education 1500-1800 (London: Longman/Pearson Education).

Jones, S. and Harvey, K. (2015) 'He should have put them in the freezer': creating and connecting through shared reading. Journal of Arts and Communities, 7 (3), $153-166$.

Kling, M. (1982) Adult reading habits. Reading Psychology, 3 (1), 59-70.

Knox, B. M. W. (1968) Silent reading in antiquity. Greek, Roman and Byzantine Studies, 9 (4), 421-435.

Liu, Z. (2005) Reading behaviour in the digital environment: changes in reading behavior over the past ten years. Journal of Documentation, 61 (6), 700-712.

Mace, J. (2012) God and Decision Making: A Quaker Approach (London: Quaker Books).

Manguel, A. (1996) A History of Reading (New York: Viking).

Mackenzie, S. (2018) The Read Aloud Family: Making Meaningful and Lasting Connections with Your Kids (London: Zondervan).

McCutcheon, R. W. (2015) Silent reading in antiquity and the future history of the book. Book History, 18 (1), 1-32.

Morton, K. (2018). Just half of three- and four-year-olds are read to every day. Nursery World, 23 February: https://www.nurseryworld.co.uk/nurseryworld/news/1163687/just-half-of-three-and-four-year-olds-are-read-to-every-day (accessed 29 March 2019).

National Institute for Literacy (2009) [Assessment 1921]. Basic Reading Skills discussion list, from 27 May 2009. www.nifl/gov/pipermail/assessment/2009/001950.html (accessed 20 June 2009). 
Ontario Ministry of Training, Colleges and Universities (2015) Ontario Adult Literacy Curriculum Framework:

http://tcu.gov.on.ca/eng/eopg/publications/OALCF_Curriculum_Framework_Mar 15.pdf (accessed 29 March 2019).

Pergams, O. (2018). A combined read-aloud think-aloud strategy improves student learning experiences in college-level biology courses. Journal of College Science Teaching, 47 (5), 10-15.

Pyrhönen, H. and Kantola, J. (Eds) (2018) Reading Today (London: UCL Press).

Radway, J. (1994) Beyond Mary Bailey and old maid librarians: reimagining readers and rethinking reading. Journal of Education for Library and Information Science, 35 (4), 275-296.

Raven, J. (1996) From promotion to proscription: arrangements for reading and eighteenth century libraries. In Raven et al., Practice and Representation of Reading.

Reading Experience Database Project (2019) The Reading Experience Database (RED), 1450-1945 (Open University) http://www.open.ac.uk/Arts/RED/index.html (accessed 29 March 2019).

Reay, B. (1991) The context and meaning of popular literacy: some evidence from nineteenth-century rural England. Past \& Present, 131, 89-129.

Reay, B. (2004) Rural Englands: Labouring Lives in the Nineteenth Century (Basingstoke: Palgrave Macmillan).

Scales, A. M. and Rhee, O. (2001) Adult reading habits and patterns. Reading Psychology, 22 (3), 175-203. 
Scholastic (2018) Reading aloud at home:

https://www.scholastic.co.uk/readingreport/reading-aloud-at-home (accessed 29

March 2019)

Sharon, A. T. (1973) What do adults read? Reading Research Quarterly, 9 (2), 148149.

Smith, M. C. (1990) Reading habits and attitudes of adults at different levels of education and occupation. Reading Research and Instruction, 30 (1), 50-58.

Snow, C. P. (1960) The Affair (London: Macmillan).

Storybook Dads (2019) Storybook Dads: https://www.storybookdads.org.uk/ (accessed 29 March 2019).

Street, B. V. (1984) Literacy in Theory and Practice (Cambridge: Cambridge University Press).

Street, B. (2003) What's 'new' in New Literacy Studies? Critical approaches to literacy in theory and practice. Current Issues in Comparative Education, 5 (2), 77 91.

Tinajero, A. (2010) El Lector: A History of the Cigar Factor Reader, Trans. J. E. Grasberg (Austin, TX: University of Texas Press).

Vincent, D. (2000) The Rise of Mass Literacy: Reading and Writing in Modern Europe (Cambridge: Polity).

Westbrook, J., Sutherland, J., Oakhill, J. and Sullivan, S. (2018) 'Just reading': the impact of a faster pace of reading narratives on the comprehension of poorer adolescent readers in English classrooms. Literacy. DOI: https://doi.org/10.1111/lit.12141

Williams, A. (2017) The Social Life of Books: Reading Together in the EighteenthCentury Home (New Haven, CT: Yale University Press). 
YouGov (2018) Read aloud 15 minutes survey report: how America reads aloud to its children:

http://www.readaloud.org/documents/ReadAloudSurveyReport.pdf (accessed 29 March 2019). 
Figure 1: Frequency of reading common text types aloud ( $\%$ of total sample)

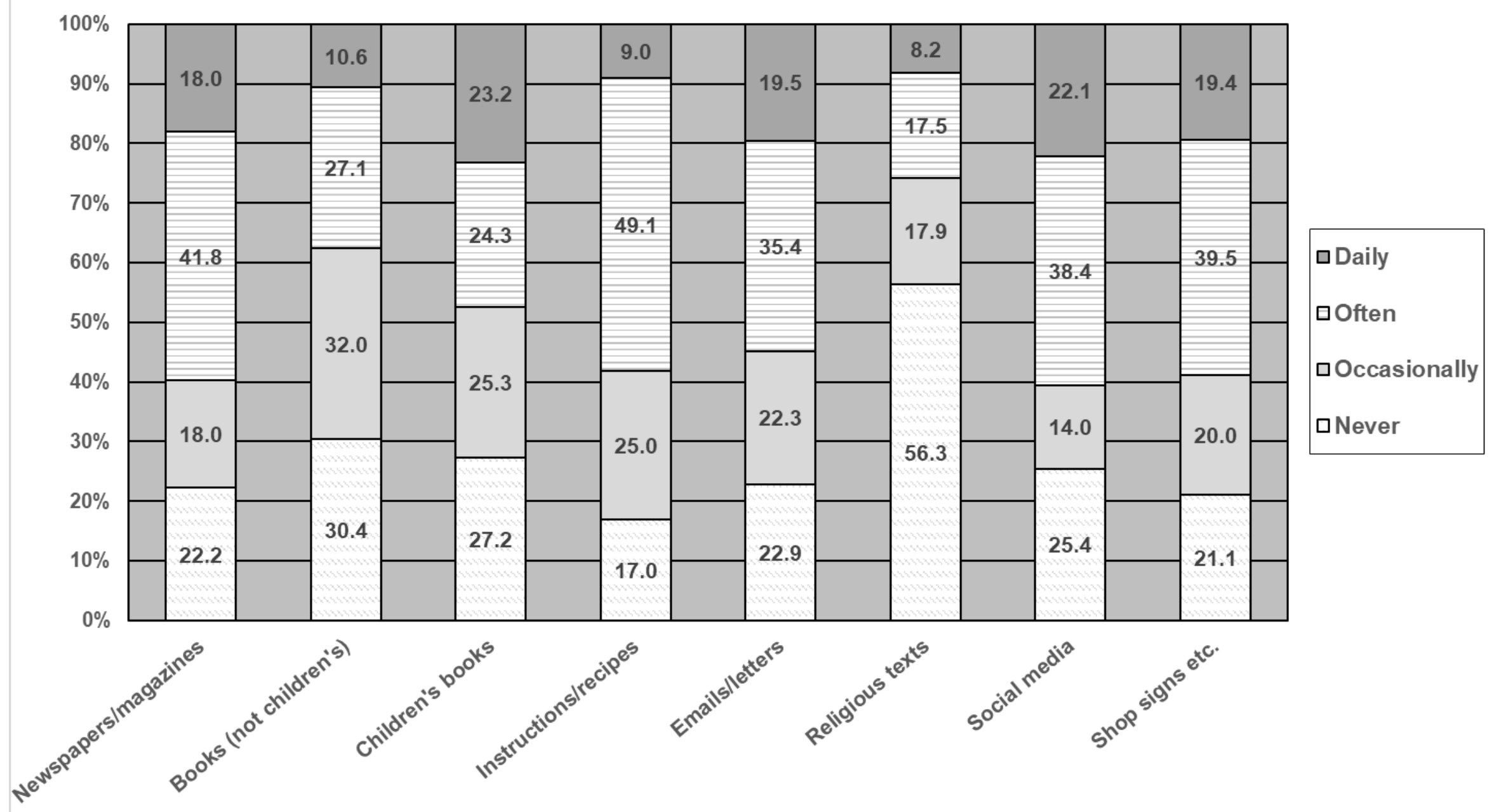


Figure 2: Frequency and formations of reading aloud ( $\%$ of total sample)

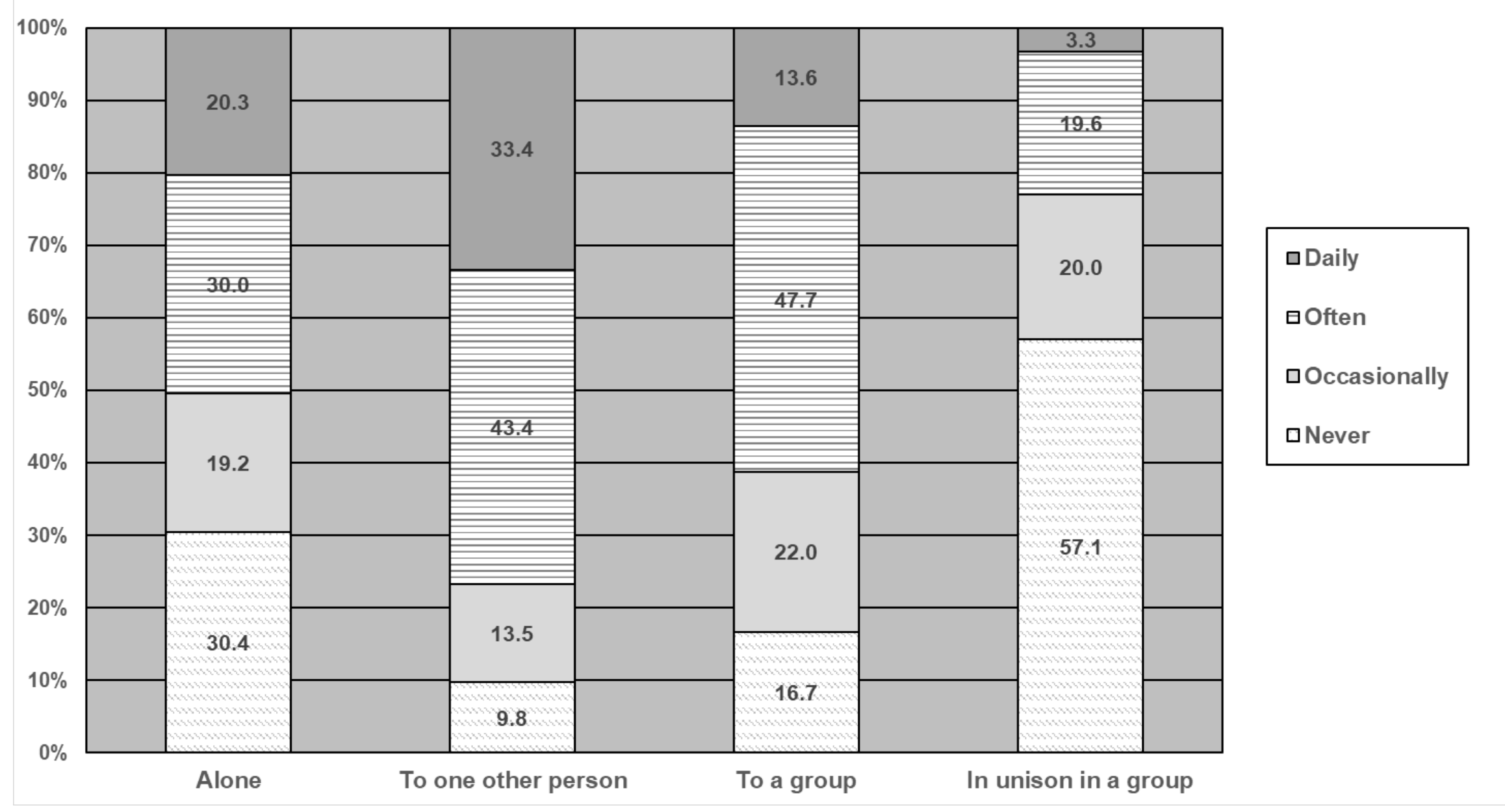


Table 1: Frequency of reading common text types aloud (\% of total), by sex

\begin{tabular}{|c|r|r|r|r|r|r|r|r|}
\hline & \multicolumn{2}{|c|}{ Never } & \multicolumn{2}{c|}{ Occasionally } & \multicolumn{2}{c|}{ Often } & \multicolumn{2}{c|}{ Daily } \\
\hline & Women & \multicolumn{1}{|c|}{ Men } & Women & \multicolumn{1}{c|}{ Men } & Women & Men & Women & Men \\
\hline $\begin{array}{c}\text { Newspapers/ } \\
\text { magazines }\end{array}$ & 19.3 & 33.0 & 18.5 & 15.6 & 44.0 & 33.9 & 18.3 & 17.4 \\
\hline $\begin{array}{c}\text { Books (not } \\
\text { children's) }\end{array}$ & 29.1 & 35.2 & 32.1 & 31.5 & 27.8 & 25.0 & 11.0 & 8.3 \\
\hline Children's books & 23.0 & 44.3 & 25.7 & 23.6 & 26.2 & 17.0 & 25.2 & 15.1 \\
\hline Instructions/recipes & 13.1 & 32.1 & 23.5 & 31.1 & 52.7 & 34.9 & 10.6 & 1.9 \\
\hline Emails/letters & 20.6 & 31.5 & 22.1 & 21.3 & 36.3 & 32.4 & 20.9 & 14.8 \\
\hline Religious texts & 53.9 & 66.1 & 18.7 & 13.8 & 18.5 & 14.7 & 9.0 & 5.5 \\
\hline Social media & 21.7 & 39.3 & 14.3 & 13.1 & 39.3 & 34.6 & 24.7 & 13.1 \\
\hline Shop signs etc. & 16.6 & 37.6 & 21.0 & 15.6 & 40.8 & 34.9 & 21.5 & 11.9 \\
\hline
\end{tabular}


Table 2: Frequency of reading common text types aloud (\% of total), by age group

\begin{tabular}{|l|r|r|r|r|r|r|r|r|}
\hline & \multicolumn{4}{|c|}{ Never } & \multicolumn{4}{c|}{ Occasionally } \\
\hline & $\begin{array}{c}\text { 30 and } \\
\text { below }\end{array}$ & $31-45$ & $46-66$ & $\begin{array}{l}67 \text { and } \\
\text { above }\end{array}$ & $\begin{array}{l}30 \text { and } \\
\text { below }\end{array}$ & $31-45$ & $46-66$ & $\begin{array}{l}67 \text { and } \\
\text { above }\end{array}$ \\
\hline $\begin{array}{l}\text { Newspapers/ } \\
\text { magazines }\end{array}$ & 20.7 & 24.4 & 19.8 & 26.3 & 24.4 & 18.2 & 16.8 & 12.3 \\
\hline $\begin{array}{l}\text { Books (not } \\
\text { children's) }\end{array}$ & 26.8 & 35.0 & 28.9 & 25.9 & 40.2 & 26.6 & 32.0 & 37.0 \\
\hline $\begin{array}{l}\text { Children's } \\
\text { books }\end{array}$ & 43.2 & 17.9 & 27.8 & 32.1 & 29.6 & 17.9 & 31.3 & 21.4 \\
\hline $\begin{array}{l}\text { Instructions/ } \\
\text { recipes }\end{array}$ & 16.0 & 13.6 & 16.9 & 29.1 & 24.7 & 20.5 & 29.9 & 21.8 \\
\hline Emails/letters & 18.8 & 24.1 & 22.5 & 25.9 & 25.0 & 17.2 & 26.0 & 20.7 \\
\hline Religious texts & 67.9 & 52.5 & 57.3 & 48.2 & 14.8 & 17.5 & 21.1 & 12.5 \\
\hline Social media & 19.5 & 25.0 & 21.8 & 49.1 & 18.3 & 13.6 & 13.9 & 9.1 \\
\hline Shop signs etc. & 14.8 & 21.9 & 20.7 & 28.8 & 22.2 & 12.4 & 27.1 & 15.3 \\
\hline
\end{tabular}

\begin{tabular}{|l|r|r|r|r|r|r|r|r|}
\hline & \multicolumn{5}{|c|}{ Often } & \multicolumn{4}{c|}{ Daily } \\
\hline & $\begin{array}{c}\text { 30 and } \\
\text { below }\end{array}$ & $31-45$ & $46-66$ & $\begin{array}{l}67 \text { and } \\
\text { above }\end{array}$ & $\begin{array}{l}30 \text { and } \\
\text { below }\end{array}$ & $31-45$ & $46-66$ & $\begin{array}{l}67 \text { and } \\
\text { above }\end{array}$ \\
\hline $\begin{array}{l}\text { Newspapers/ } \\
\text { magazines }\end{array}$ & 41.5 & 39.2 & 46.0 & 35.1 & 13.4 & 18.2 & 17.3 & 26.3 \\
\hline $\begin{array}{l}\text { Books (not } \\
\text { children's) }\end{array}$ & 28.0 & 23.7 & 29.9 & 25.9 & 4.9 & 14.7 & 9.1 & 11.1 \\
\hline $\begin{array}{l}\text { Children's } \\
\text { books }\end{array}$ & 18.5 & 17.3 & 27.3 & 44.6 & 8.6 & 46.9 & 13.6 & 1.8 \\
\hline $\begin{array}{l}\text { Instructions/ } \\
\text { recipes }\end{array}$ & 53.1 & 55.1 & 44.3 & 41.8 & 6.2 & 10.8 & 9.0 & 7.3 \\
\hline Emails/letters & 32.5 & 35.1 & 36.5 & 36.2 & 23.8 & 23.6 & 15.0 & 17.2 \\
\hline Religious texts & 13.6 & 16.9 & 16.1 & 30.4 & 3.7 & 13.0 & 5.5 & 8.9 \\
\hline Social media & 30.5 & 36.9 & 46.5 & 25.5 & 31.7 & 24.4 & 17.8 & 16.4 \\
\hline Shop signs etc. & 39.5 & 41.6 & 38.9 & 35.6 & 23.5 & 24.2 & 13.3 & 20.3 \\
\hline
\end{tabular}


Table 3: Reasons for reading aloud: \% answering 'yes' to question 'Do you ever read aloud for these reasons?'

\begin{tabular}{|l|r|r|r|r|r|r|r|}
\hline & \multicolumn{1}{|c|}{} & \multicolumn{2}{|c|}{ By sex } & \multicolumn{4}{|c|}{ By age group } \\
\hline & \multicolumn{1}{|c|}{ All } & Female & \multicolumn{1}{|c|}{ Male } & $\begin{array}{c}30 \text { and } \\
\text { below }\end{array}$ & 31 to 45 & $\begin{array}{c}46 \text { to } \\
66\end{array}$ & $\begin{array}{c}67 \text { and } \\
\text { above }\end{array}$ \\
\hline To share what I have read with someone & 88.5 & 90.8 & 80.4 & 92.7 & 86.6 & 91.7 & 77.4 \\
\hline To a child & 72.0 & 74.9 & 60.7 & 61.0 & 79.9 & 70.4 & 69.4 \\
\hline To memorise or learn something & 70.7 & 74.2 & 58.0 & 75.6 & 68.7 & 73.8 & 59.7 \\
\hline To understand difficult text & 67.5 & 71.0 & 55.4 & 76.8 & 64.2 & 68.9 & 59.7 \\
\hline To entertain others & 66.5 & 68.6 & 58.9 & 64.6 & 63.7 & 71.8 & 59.7 \\
\hline To help someone & 62.8 & 67.1 & 46.4 & 70.7 & 59.8 & 66.5 & 48.4 \\
\hline To help me write something & 59.9 & 62.6 & 50.0 & 62.2 & 55.3 & 62.6 & 61.3 \\
\hline Because I enjoy it & 56.0 & 58.5 & 46.4 & 53.7 & 52.0 & 60.7 & 54.8 \\
\hline To help read/learn another language & 55.0 & 58.0 & 44.6 & 59.8 & 55.3 & 54.4 & 50.0 \\
\hline Part of communal religious worship & 31.8 & 33.1 & 26.8 & 23.2 & 34.6 & 30.6 & 38.7 \\
\hline Individual worship/spiritual purposes & 26.3 & 27.8 & 20.5 & 23.2 & 28.5 & 24.8 & 29.0 \\
\hline
\end{tabular}

Note: Figures given in descending order of \%age of whole sample answering 'yes'. 
Table 4: Reading aloud from computer, tablet and phone screens (\% of sample, and by sex and age group)

\begin{tabular}{|l|r|r|r|r|r|r|r|}
\hline & & \multicolumn{2}{|c|}{ By sex } & \multicolumn{4}{c|}{ By age group } \\
\hline & \multicolumn{1}{|c|}{ All } & Female & \multicolumn{1}{c|}{ Male } & $\begin{array}{c}\text { 30 and } \\
\text { below }\end{array}$ & \multicolumn{1}{|c|}{$31-45$} & $46-66$ & $\begin{array}{c}67 \text { and } \\
\text { above }\end{array}$ \\
\hline Yes & 77.9 & 81.2 & 65.2 & 89.0 & 76.5 & 81.1 & 56.5 \\
\hline No & 20.6 & 17.1 & 33.9 & 11.0 & 22.3 & 17.0 & 40.3 \\
\hline
\end{tabular}


Table 5: Frequency of hearing common text types read aloud (\% of total), by sex

\begin{tabular}{|c|r|r|r|r|r|r|r|r|}
\hline & \multicolumn{2}{|c|}{ Never } & \multicolumn{2}{c|}{ Occasionally } & \multicolumn{2}{c|}{ Often } & \multicolumn{2}{c|}{ Daily } \\
\hline & Women & \multicolumn{1}{|c|}{ Men } & Women & \multicolumn{1}{|c|}{ Men } & Women & Men & Women & Men \\
\hline $\begin{array}{c}\text { Newspapers/ } \\
\text { magazines }\end{array}$ & 32.3 & 42.1 & 24.6 & 17.8 & 32.8 & 26.2 & 10.4 & 14.0 \\
\hline $\begin{array}{c}\text { Books (not } \\
\text { children's) }\end{array}$ & 47.7 & 57.5 & 29.1 & 25.5 & 19.4 & 14.2 & 3.8 & 2.8 \\
\hline Children's books & 41.4 & 57.1 & 19.2 & 16.2 & 25.7 & 18.1 & 13.7 & 8.6 \\
\hline Instructions/recipes & 32.2 & 47.2 & 27.8 & 25.5 & 35.8 & 24.5 & 4.1 & 2.8 \\
\hline Emails/letters & 35.4 & 43.1 & 21.7 & 17.4 & 33.6 & 32.1 & 9.3 & 7.3 \\
\hline Religious texts & 49.9 & 62.0 & 20.9 & 16.7 & 23.9 & 15.7 & 5.2 & 5.6 \\
\hline Social media & 30.4 & 43.1 & 12.6 & 11.0 & 44.0 & 33.0 & 13.1 & 12.8 \\
\hline Shop signs etc. & 29.4 & 48.1 & 23.4 & 22.6 & 36.9 & 24.5 & 10.2 & 4.7 \\
\hline $\begin{array}{c}\text { Audiobooks or } \\
\text { books on radio }\end{array}$ & 33.8 & 41.5 & 21.9 & 24.5 & 27.9 & 21.7 & 16.4 & 12.3 \\
\hline
\end{tabular}

